\title{
Small town identity and history's contribution to a response in policy change: a case study of transition from coal to biomass energy conversion
}

\author{
Jason Ernest Elvin Dampier ${ }^{1 *}$, R Harvey Lemelin ${ }^{2}$, Chander Shahi ${ }^{1}$ and Nancy Luckai ${ }^{1}$
}

\begin{abstract}
Background: In 2002, the provincial government of Ontario first announced plans to close all coal-burning thermoelectric generating stations. Facing the loss of local jobs should the local generating station close, Atikokan, Ontario, residents responded. This research seeks to answer the following question: What are Atikokan's historical pre-conditions and residents' attributes and perceptions which likely lead to the community's response, and do these characteristics relate back to the broader body of knowledge?

Methods: Our study investigates the Atikokan Generating Station (AGS) conversion from coal to biomass wood pellets as a case, exploring the extent to which the community's identity played in response to the policy change. The current study takes a qualitative data analysis approach utilizing interviews with community members, current newspaper articles, past relevant consultant reports and archival data. Data collected were coded to themes using NVivo 10 software. Four emergent themes were identified and cross-validated.

Results: The emergent themes are i) traditions of resource-based industry congruent with producing and burning forest-based renewable fuels, ii) historical linkages to a strong entrepreneurial ethic, iii) community members' recognition of AGS's multifaceted role in the community and iv) strong community spirit and desire to fight for their town. These themes appear to have been prerequisite in order to successfully engage provincial government, and we demonstrate that these findings are somewhat corroborated back to the broader literature.

Conclusions: Furthermore, as power generating authorities elsewhere grapple with demands to reduce carbon emissions, the Atikokan case may provide insight for other jurisdictions evaluating renewable energy adoption.
\end{abstract}

Keywords: Bioenergy; Atikokan Generating Station; Lignite coal; Social impacts; Wood pellets

\section{Background}

Rural and small towns can be defined as having an urban core of less than 10,000 people and being 'outside the commuting zone of centres with population of 10,000 or more' [1]. These communities are often seen as possessing a trusting network of strong interpersonal relationships $[2,3]$. Furthermore, the history, attributes and perceptions of the citizens can be important factors contributing to this identity. How community members see themselves can contribute to the social capital which small towns use to solve problems while facing crisis.

\footnotetext{
* Correspondence: jedampie@lakeheadu.ca

${ }^{1}$ Faculty of Natural Resources Management, Lakehead University, 955 Oliver Road, Thunder Bay, Ontario P7B 5E1, Canada

Full list of author information is available at the end of the article
}

On 9 September 2002, a trajectory regarding energy policy in Ontario was established when former Premier Dalton McGuinty publically referred to the coal used in thermoelectric power generation as, 'Environmental enemy number one. It is $19^{\text {th }}$ century. It is dirty. It is dangerous. And we're going to get rid of it' [4]. These were provocative statements, especially considering that in 2002 over $20 \%$ of the electricity produced in Ontario was from four coal-fired generating stations. In total, these four coalfired stations, publically owned by Ontario Power Generation (OPG), accounted for over 3,300 megawatts (MW) capacity and employed approximately 770 people [5-8]. Shortly after the announcement, an initial plan and timeline was revealed, which would see the decommissioning and closure of all coal-based generating stations in

\section{实}


Ontario. If implemented as originally proposed, replacement generation capacity would have come from other generating stations (such as hydroelectric or nuclear) in other communities [9]. Current Ontario Premiere Kathleen Wynne framed the argument not in terms of a feasible business case for power production, but rather in terms of government savings in other domains.

'Becoming a coal-free province is the equivalent of taking up to seven million cars off the road, which means we'll have cleaner air to breathe, while saving Ontario \$4.4 billion in health, financial and environmental costs [10]'.

If implemented as originally proposed, these closures would have led to reductions in generating capacity for Ontario, the loss of direct OPG jobs and the loss of indirect and induced benefits created by these jobs. Of the four communities where OPG operated coal-fired thermoelectric power generating stations, the small isolated community of Atikokan (48 45' $0^{\prime \prime} \mathrm{N}, 91^{\circ} 37^{\prime} 0^{\prime \prime} \mathrm{W}$; $393 \mathrm{~m}$ above sea level) in northwestern Ontario was presumed to be the most vulnerable due in part to its remoteness and reduced opportunities for employment should the generating station close. Atikokan's nearest neighbouring centres include Thunder Bay (population approximately 110,000) $200 \mathrm{~km}$ to the west, Fort Frances (population approximately 8,000) $150 \mathrm{~km}$ to the east and Dryden (population approximately 7,500) $200 \mathrm{~km}$ to the north. Adding to the sense of isolation, the community is not serviced by passenger flights or passenger rail and only has bus service three times a week. This is in stark contrast to the other three OPG generating stations which are either in a major centre, as is the case with Thunder Bay Generating Station, or closer to major centres in more densely populated Southern Ontario, as is the case for both Lambton and Nanticoke Generating Stations.

The Town of Atikokan was established in the early 1900s when the Canadian Northern Railway (later the Canadian National Railway) built a divisional point near the town centre. Rail divisional points were required during this era in order to resupply locomotives with water and coal. They were partly responsible for establishing small communities across Canada by providing local railway jobs [11]. During this time, Atikokan had a population of about 250 to 300 people (O Boland, unpublished document), and train transportation was the only way to access the community. The road to Port Arthur (now Thunder Bay) was built in 1954 and the road to Fort Frances was built in 1967 (O Boland, unpublished document), further illustrating the community's isolation for approximately half of its existence.

Despite its isolation, the town experienced some population growth in the 1930s when high-grade iron ore was discovered and mined nearby and, again, in the 1940s when the ore was used to support the war effort $(\mathrm{O}$ Boland, unpublished document). After the war, the mines continued operating until the last two were closed in 1979 and 1980 (O Boland, unpublished document) [12], making forestry the only remaining major employer in the post-mining era [13]. Without mining as the community's base industry, the town faced an uncertain future. This uncertainty sparked the community to successfully lobby the Ontario government to build the Atikokan Generating Station (AGS), which was commissioned in 1985 at a construction cost of $\$ 750$ million. Adding new power generating jobs to the existing forestry jobs helped stabilize the community's economy. However, in 2008, the community experienced a collapse in the forest sector, which had wide-reaching negative effects on the community [14]. This, coupled with the possibility of losing approximately 90 well-paying jobs at the AGS due to the provincial coal cessation policy [15], further exacerbated economic worries.

As details on the proposed coal cessation were being worked out, and community-level impacts anticipated, the provincial government promised the Town of Atikokan that the community would not experience negative effects by changes in the policy. The government's commitment became more clear when the Minister of Energy, Dwight Duncan, stated in the provincial legislature on 2 May 2005 that, 'The people of Atikokan have had our assurance that plant, when it is closed - will be replaced with 90 new jobs' [4]. This promise was welcomed by the community; however, without a clear commitment of resources, it was received with some doubt. According to Liberal Member of Provincial Parliament (MPP) for Thunder BayAtikokan, Bill Mauro, doubts were allayed when the first tangible sign of financial commitment came in the 2006 provincial budget [16]. In that year's budget, the government responded to the community's lobbying when $\$ 4$ million were allocated to establish the Atikokan BioEnergy Research Centre (ABRC) with its stated goal 'to explore cleaner forms of electricity generation and encourage economic opportunities in Ontario's north' [17]. The research centre was composed of 29 professors and 87 students from Ontario colleges and universities and ran from 2007 to 2010 [17]. The ABRC stimulated interest in non-coal fuel sources for thermoelectricity production, and when the Liberal government signed into law legislation banning coal use in power generation [18], forest biomass $^{\mathrm{a}}$ was seen as a potentially viable alternative to coal. This commitment of funds also suggested that the government's ultimate desire to find a solution would keep the AGS operating. Research generated from the centre and other sources suggested that although the AGS was originally designed to burn lignite coal, alternative fuels existed and included peat, unutilized wood, forest harvest 
residues and wood mill waste [19]. Ultimately among the competing fuel options, the research indicated that the generating station could burn biomass wood pellets since pellets could be designed similarly to lignite $[9,17,20]$. An additional local benefit of burning pellets included the creation of a local value chain from underutilized forest trees species and unutilized forest product wastes.

Proof-of-concept testing with biomass wood pellets began at the AGS in 2008. During one of these tests, AGS experienced a setback, when a dust explosion occurred. Although no one was injured, the facility sustained damage [20]. The incident review ultimately led to the identification and implementation of major fuelhandling modifications in order to safely handle biomass fuels [20]. With these modifications, the once 100\% coal-burning generating station was transformed to a $100 \%$ biomass wood pellet-burning station, making this conversion one of the world's largest at this scale and making AGS the largest 100\% biomass thermoelectric generating station in North America (at the time of publication) [21].

\section{Literature review}

Academic peer-reviewed journal articles and the grey literature indicate that the most successful and resilient isolated, rural communities tend to possess at least one strong base industry which oftentimes is linked to a primary resource sector such as agriculture, fishing, forestry, energy or mining [22-24] or to other industries such as tourism, government administration or defence [25]. Furthermore, communities that possess an empowered and engaged populous can be successful in reaching their specific goals [26]. Another important factor in community success is related to the perception of commuting distance to a larger centre, which can often provide jobs when local jobs disappear [25,27].

The literature also indicates that communities which rely on primary resource industries can be vulnerable to external factors such as volatile commodity prices and fluctuations of the resource [25,28-31]. Although potentially vulnerable, rural communities with strong base industries also can experience increased employment rates, good income levels, lower cost of living, affordable housing, lower crime rates and opportunities to participate in volunteer groups $[28,32]$. Communities with the ability to identify potential vulnerabilities and anticipate potential economic and social shocks are often more successful and resilient long-term [3,33].

According to Rosehart, successful communities in northwestern Ontario generally require i) a stabilized economy, ii) capacity building for the new economy and iii) growth for a prosperous economy [24]. Had the coal cessation policy led to the closure of the AGS, these necessities for socio-economic well-being would have gone unmet and the decision would have likely i) destabilized the Atikokan economy, ii) reduced capacity for new economic activities and iii) shrunk and impoverished Atikokan's population.

We developed the following problem statement for the current research. Faced with similar socio-economic challenges, such as the loss of a major employer, some communities have collapsed while others have found creative ways to survive and adapt [33-35]. But it is not always clear why communities respond to threats in the manner that they do. When Atikokan residents realized that the community's major employer, the AGS, was potentially slated for closure, they did not take a passive role. This study strives to answer the following research question: What are Atikokan's historical pre-conditions and residents' attributes and perceptions which likely lead to the community's response, and do these characteristics relate back to the broader body of knowledge? Through a historical and contemporary lens, we view this as a timely research opportunity, which may provide insight for other communities facing major employer loss, evaluating the adoption of renewable energies, engaging in sustainability and developing overall community readiness.

\section{Methods}

This paper employs a qualitative data analysis approach, utilizing 1) interviews with community members, 2) current newspaper articles, 3) past relevant consultant reports and 4) archival data.

\section{Data collection}

During the summer of 2013, 25 in-depth semi-structured interviews were conducted. We purposefully sampled highly knowledgeable participants in order to gather professional and expert observations and perceptions related to Atikokan's local economy, social activities, industrial activity and conversion at the AGS. The criteria included:

a) having a direct connection to business, governance, entrepreneurship or industry activities within Atikokan,

b) having a good historical knowledge of Atikokan's natural resource-based economy (i.e. forestry, mining, etc.),

c) having a knowledge of the new industrial processes which will be introduced to the Atikokan economy (i.e. wood pellet production and supply value chain).

Participant selection was conducted with the purpose of ensuring that the research question would be addressed, while including some participant diversity, thus allowing for a range of participant points of view [36]. For example, when participants from the same organization 
were interviewed, we looked for participants with a variety of job responsibilities or years in the community. Purposeful participant sampling continued until data saturation was reached, which was the point when 'no new analytical insights [were] forthcoming' [36]. It appeared that data saturation began to occur after interviewing the 16th participant.

Questions posed to participants were generally semistructured $[36,37]$ and pertained to occupation, years in community, recreational activities and participation levels in the local economy. Participants were also asked to what extent the AGS contributes to the local economy and their perceptions of how future woody biomass burning might affect the town's economy.

After the initial transcription and preliminary first round of interview coding, we randomized the order of the interviews and conducted a second round of coding to help ensure interviews had sufficient coding coverage. In order to ensure our coding and content analysis was valid and replicable, direct participant quotes were included whenever possible. These direct quotes explicate our coding inferences and themes [38,39].

Based on the aforementioned participant selection criteria, 25 interviews were conducted with 20 community members. Due to the depth of some participants' knowledge, follow-up interviews were required. Participants represented the following distinctions: municipal and provincial government, economic development, entrepreneurism and business, health care, power generation, forest products industry, tourism and culture, and education. Thirteen of the 20 participants, or $65 \%$, have lived in Atikokan for over 15 years, with 4 participants living in the community less than 5 years. Three participants do not live in Atikokan, but have a strong connection and knowledge of the community. Most interviews were audio-recorded totaling over $30 \mathrm{~h}$ of recorded audio, with over $20 \mathrm{~h}$ transcribed for further analysis. In the instances where the interview was not recorded, we relied solely on research notes collected during the interview.

Participants were given the choice to either remain anonymous or disclose their identity. For individuals wishing to remain anonymous, all identifying characteristics were stripped from their interview transcripts. All participants directly quoted were contacted via follow-up email to ensure accuracy of the quote as well as to confirm ongoing consent. Participants were invited to review a summary of the findings via email or phone, prior to submission for publication.

In addition to interviews, local newspaper articles printed in the Atikokan Progress ${ }^{\mathrm{b}}$ from 2008 to 2013 were collected. Criteria for newspaper article selection followed similar criteria for participant selection (i.e. articles reporting Atikokan's local economy, social activities, industrial activity and conversion at the AGS). We focused on this interval because it marks the time period covering the conclusion of the ABRC work, through to the commencement of approvals and conversion of the AGS.

Finally, all relevant, applicable and available communitylevel consultant reports $(n=16)$ were included. Over the years, studies were commissioned by various groups (such as the now defunct Quetico Centre) as well as the currently operating Atikokan Economic Development Corporation (AEDC) which is a non-profit, community-based corporation. These reports were selected on the basis of being congruent or peripheral to our research objectives and were used to provide a basis for cross-validation and contextual depth. Reports commissioned by the AEDC were particularly useful since their mandate is somewhat aligned with the study's research question. The AEDC's goals are to work in partnership with the people of Atikokan and the surrounding areas, to generate and maintain permanent employment through the creation and support of self-employment initiatives and economicbased community projects' [40]. Furthermore, relevant historical and archival community data were collected from the Atikokan Centennial Museum's archives.

\section{Data analysis}

Each interview was transcribed, and then checked against the audio recordings for accuracy, before being imported into the Computer Assisted Qualitative Data Analysis Software (CAQDAS) NVivo 10 [41]. Since the interviews were semi-structured and open-ended (allowing participants to speak freely), we followed a qualitative data analysis approach $[38,42]$. Upon transcription, each interview was initially coded [39] to themes based on the research question. New coding themes emerged through the process and were included and integrated into a nested coding structure (Appendix). As the NVivo 10 software was populated with more interviews, an iterative process was employed in order to 'back-fill' previous interviews with appropriate codes.

Four key themes emerged, providing insight into the historical community pre-conditions which created a cultural climate conducive for the conversion to take place. These themes also provided insight into the current community attributes and perceptions which supported the transition to biomass. The themes include:

i. traditions of resource-based industry congruent with producing and burning forest-based renewable fuels,

ii. historical linkages to a strong entrepreneurial ethic,

iii. community members' recognition of AGS's multifaceted role in the community and

iv. strong community spirit and desire to fight for their town. 
After the interviews were coded, all other sources were then imported and coded in the CAQDAS. Coded content from the interviews, newspaper articles, consultant reports and archival data were then analysed using NVivo 10's coding query and matrix coding query functions. Themes were initially assessed using frequency counts based on source, versus themes which addressed the research question. Summary results are presented in table form (Table 1), followed by an explication of coded themes by inclusion of direct quotes and paraphrases from interview participants, newspaper articles, consultant reports and archival data.

We only accepted emerging themes as potentially valid when they reoccurred. When a theme occurred once, it may have been an accident, twice was considered a coincidence, and three or more occurrences (from different participants) suggested that the theme occurrence was beyond mere chance and a pattern was emerging in the data [43].

\section{Results and discussion}

The results of the matrix coding query are presented in Table 1 and display the four emergent themes as they were coded within each data source. The table indicates that the four themes exceed the minimum three occurrence rule we established, a priori [43]. For example, for each of the four coded themes, occurrence rates range from 27 to 44 summed across all sources.

Table 1 also includes the number of sources where a particular theme was detected. For example, our analysis included 20 interview participants of which 19 interviews mention the traditions of resource-based industry congruent with producing and burning forest-based renewable fuels, 15 mention historical linkages to a strong entrepreneurial ethic, 17 mention community members' recognition of AGS's multifaceted role in the community and 13 mention a strong community spirit and desire to fight for their town. Not all sources are included in the explication below since some redundancy of content occurred.
Traditions of resource-based industry congruent with producing and burning forest-based renewable fuels Data from participant interviews, newspaper articles, consultant reports and archives indicate that the Atikokan area has a long tradition of natural resource-based industries which include forestry and forest products (as well as mining, however, mining falls outside the scope of the current study). These industries are viewed as positive contributors to the local economy, and there appears to be comfort among community members with its continuation and expansion in light of changes at AGS and the nascent wood pellet industry.

Historical underpinnings are outlined by McEvoy and Gustafson in 1985 [44]. They report that the early 1900s saw the initiation of modern forest operations when lumberman J.D. McArthur first brought, 'machinery to Atikokan and set up a sawmill two miles west of the town'. The mills were mobile units, and for years, this was how wood was processed in the region. McEvoy and Gustafson's report is further elaborated by material from Atikokan Mayor Dennis Brown's interview, which discussed the transition from mobile mills to stationary mills. Mayor Brown,

'The first stationary lumber mill was constructed in Sapawe in 1945. The mill was eventually completed, renovated and updated, a dry kiln was erected, equipment to strip the bark from logs and chipping facilities installed'.

Regardless of whether the forest product mills were mobile or stationary, they required a secure supply of raw material creating the necessity for local forest and logging operations. Longtime resident Owen Boland, in an unpublished report, provides additional historical context for the Atikokan area forest operations.

'Until the 1940's, bush operations in this area were seasonal. Trees were cut over winter, floated downstream the next summer and kept feeding the saw mills until the lakes froze over and logs could no

Table 1 Community themes emerging from qualitative data analysis displayed by data source frequency counts

\begin{tabular}{|c|c|c|c|c|c|}
\hline \multirow[t]{2}{*}{ Theme } & \multicolumn{5}{|c|}{ Source } \\
\hline & $\begin{array}{l}\text { Interview } \\
\text { participants }\end{array}$ & $\begin{array}{l}\text { Consultant } \\
\text { reports }\end{array}$ & $\begin{array}{l}\text { Newspaper } \\
\text { articles }\end{array}$ & $\begin{array}{l}\text { Archival } \\
\text { data }\end{array}$ & Total \\
\hline $\begin{array}{l}\text { i) Traditions of resource-based industry congruent with producing and burning } \\
\text { forest-based renewable fuels }\end{array}$ & 19 & 8 & 15 & 2 & 44 \\
\hline ii) Historical linkages to a strong entrepreneurial ethic & 15 & 3 & 7 & 2 & 27 \\
\hline iii) Community members' recognition of AGS's multifaceted role in the community & 17 & 4 & 6 & 0 & 27 \\
\hline iv) A strong community spirit and desire to fight for their town & 13 & 6 & 4 & 5 & 28 \\
\hline Total number of sources & 20 & 16 & 46 & 26 & \\
\hline
\end{tabular}


longer be floated to the mill's jack ladder, by which they were fed to the mill's saws'.

With the mine closures in the late 1970s and early 1980s, forestry jobs increased in importance within the region. A 1980 article in the Atikokan Progress states, 'After the mines shut down, over 400 jobs were produced in Atikokan with forestry becoming the major employer' [13], and in 1993, Paulsen [45] reported the importance of forest jobs as 'the major employer'.

But the status of the forest industry as the major employer was diminished after the 2008 housing market crash due to reductions in demand for lumber. Mayor Brown outlined the decline and rebound of the forest products industry in Atikokan, suggesting that the community may once again accept and embrace forestrelated industries.

'At one time, we had two forest-related plants operating ... they both closed in 2008. Now the Fiber Tech mill is coming back; a new company, Rentech, bought it. They're going to start making the wood pellets and wood biomass'.

The signs of forest industry recovery being recognized by community members are also captured in AEDC's Chairperson Dave Elder's interview.

'The forest industry is seeing a little bit of a turn around. Guys are cutting wood. Guys are hauling wood. The sawmill [planned to be built] of course is an obvious indication of that'.

These observations are furthermore, optimistically portrayed in the Atikokan Progress in 2010.

'And even on the forestry front, some small successes are evident. The AEDC continues to assist Atikokan Renewable Fuels ${ }^{\mathrm{c}}$ as it turns the former Proboard manufacturing plant into a wood pellet plant, and to press for a bio-energy fuelled future for the Atikokan Thermal Generating Station [46]'.

It should be noted, however, that although the aftermath of the 2008 housing crash left the forest products industry in decline, the managed forest near Atikokan has performed well relative to other forest management units within Ontario. One participant commented that the Crossroute Forest has been the busiest forest in Ontario throughout the downturn averaging over one million cubic metres per year. The Crossroute's performance during the decline suggests that the region has a strong forestry sector, which could integrate well with new wood pellet production facilities. In addition to the forest sector's perceived strength, Mike McKinnon, Atikokan Progress co-editor, states how some community members support the use of locally produced biomass wood pellets, rather than a fuel source from two provinces away.

'The nice part of it is that it's a support for the forest industry, which is something we're very familiar with here and have been involved with since day one. It makes it almost a more ... an organic thing than coal from Saskatchewan, the province comes in and plops this billion-dollar facility in and then they ship the coal in from Saskatchewan ...'

Furthermore, sociologist Chris Southcott [47] reports that 'blue-collar' industry jobs (such as mining and forestry) have been the largest single group of jobs in the regional economy, suggesting that increased activity in logging, forestry and forest product manufacturing is what many in the region know, and thus welcomed. Although this view seems to be dominant in Atikokan, at least one community member considers a potential economic weakness with burning wood biomass,

'Even four years ago I was still thinking coal's for burning and wood's for building. I'm not sure that woody biomass is the greatest answer. It's got to be used pretty judiciously, which pushes the cost to crazy levels'.

A Community Resilience Model proposed by Akamani (2012) further develops the idea of communities doing what they know. It draws on rural sociology and resilience theory and suggests that a forest-based community's structures and processes can lead to that community's ability to adapt and respond to change [48]. Forest communities may tend to remain on current or historically familiar trajectories rather than assuming new and unknown ones due to its familiarity. Often, communities with strong mines, mills or other extractive sectors tend to see those sectors as permanent. Freudenburg and Gramling in 1992 illustrate this point by reporting that 'children of miners, mill workers, and roughnecks can grow up thinking of such employment as being stable or predictable' [49].

\section{Historical and current linkages to a strong entrepreneurial ethic}

In addition to traditions of resource-based industries congruent with forest-based fuels, another theme emerged which was related to Atikokan's historical and current linkages to a strong entrepreneurial ethic. Having a local entrepreneurial ethic likely played an important role in how the community explored creative solutions, and petitioned government, in response to coal cessation at AGS. 
Interview data from Garry McKinnon, the AEDC Executive Director, explains how he believes the dynamic works in Atikokan.

'We're evolutionary beasts. We change and adapt based on needs. If there isn't a need for entrepreneurship in that community, for you to meet those levels in the Maslow, like Maslow's Hierarchy of Needs, then you won't develop entrepreneurial skills'.

This entrepreneurial notion is corroborated by longtime resident and serial entrepreneur Vic Prokopchuk, who noted that the town's isolation and independence during its early days may have been a factor in developing local entrepreneurs.

'There was no road from Fort Frances or Thunder Bay ... You wanted something done, or you want to start something or have something available, you [had to do it yourself]. So maybe the entrepreneurship was sort of forced on you ... Everything [was shipped] by train you see. You came in and went out by train. I think that must be a big contributor to the incentive to be an entrepreneur'.

The isolation, coupled with creative, highly skilled agricultural backgrounds of some community members, according to McKinnon, may have also played a role in the development of the community's entrepreneurship.

'Two things emerged as a result of that need. High creativity ... high skills in terms of ... if you needed a part, if you needed a solution, somebody ... and an awful lot of the population had agricultural backgrounds which is typical for farmers. If I got to fix it, I'll figure out a way to fix it'.

In addition to the community's isolation, Prokopchuk also attributes the community's entrepreneurial spirit to a mine boss known as Pop Fatheringham during Atikokan's iron ore mining days. Fatheringham may have fostered a culture of entrepreneurship by creating worker incentives which contributed to Atikokan's early development.

'I was staying at the bunkhouse at the mine site at that time. Since I had some electrical and telecommunications experience - after work I joined the crew of volunteer pipefitters, carpenters, electricians. We build that hospital. I think for every hour you volunteer, they pay you one. Something like that anyway'.
Dave Elder also suggests that the entrepreneurial spirit in Atikokan may be linked to the former mining industry and the types of people the mines attracted.

'You had a lot of people coming in that had to be self-starters. There were companies to work for, but then there was all kinds of opportunity for support and services of the various companies ... It does seem to be, for whatever reasons, a spirit of entrepreneurism'.

Potentially an outgrowth of the mining era's entrepreneurial spirit, the Atikokan Industrial Development (AID) Committee was established and tasked with ensuring Atikokan would survive and thrive after the mine closures. According to Paulsen's (1993) report,

'Between 1972 and 1978, much of Atikokan's infrastructure was dramatically improved as a result of the AID Committee and the Township council's efforts. A swimming pool, nine hole golf course, curling rink, airport and a new hospital were built. Despite the impending closures, they wanted to make Atikokan a good place to live in the future' [45].

Present-day community's entrepreneurial initiatives are often championed by the AEDC. Garry McKinnon, AEDC Executive Director, comments on the organization's current role in supporting entrepreneurial opportunities.

'It's whatever is necessary to make that budding entrepreneur's dream come true. We'll do almost anything. From some of the creative stuff in terms of their marketing materials and to the mundane cash flow projections that the banks produce that are so foreign to most of them'.

Although the AEDC strives to support budding entrepreneurs, one participant observed that some of the AEDC's efforts are viewed critically by local people.

'[The AEDC] gets a lot of criticism because the other people try to do those things and the same old, "That's my tax dollars and it's used to compete against me." From Garry [McKinnon's] point of view, for the health of the community, we need that business. He may get criticized for this, but he usually does a pretty good analysis of it, like what caused the business to fail, is it just because the business shouldn't exist or is it because management did some interesting things that they shouldn't have done'.

Additional interviews however, suggest that the community's entrepreneurial spirit is not that straightforward. Warren Paulsen provides an alternative view on 
how entrepreneurial spirit develops within the community. It can also be a function of attracting outside entrepreneurs, rather than developing them from within. 'The entrepreneurship comes from outside. You have to figure out a way to draw those people in. It's a little tough'. And Mayor Brown's interview reveals a similar theme.

'We don't have enough entrepreneurs in Atikokan. We have opportunities but we have nobody to take the lead. That is something that's out there. I think that's a similar situation in most small towns'.

Regardless of whether the entrepreneurial spirit develops locally, or is imported as people moved to the community, the historical and current linkages to a strong entrepreneurial ethic are certainly present. This spirit likely played a role when the community faced coal cessation and the subsequent development of a local biomass wood pellet industry. As referred to earlier, the wood pellet manufacturer (Atikokan Renewable Fuels, and then Rentech) saw the entrepreneurial opportunity of supplying AGS, as well as growing the market. A participant with knowledge of the local economy comments,

'What they're [Rentech] selling to OPG is the capacity of one press basically you know they're putting in four or five presses ... So they are going to sell $75 \%$ or $85 \%$ of their production outside of the community. But that'll look good you know you got 25 direct jobs, probably you're going to result in 60 or 70 indirect and how many induced'.

An entrepreneurial ethic in other communities seems to play a role in community resilience and prosperity, and in recent years, its value has been more broadly recognized $[50,51]$. In a study from Costa Rica, entrepreneurial drive in the community of La Fortuna was identified as an important aspect of community member identity as they had to 'battled nature' to set up the town [52]. On the rural landscape, a strong entrepreneurial ethic serves many positive roles such as the delivery of goods and services and the maintaining social fabric [53,54].

Entrepreneurial ethic coupled with the next two themes (community members recognize the positive role AGS plays in the community, and strong community spirit and desire to fight for their town) seemed to have synergistically contributed to the community's overall identity and supported community efforts to effectively influence energy policy makers.

\section{Community members' recognition of AGS's multifaceted role in the community}

Base industries help keep isolated communities strong by providing jobs and other associated socio-economic benefits. When these industries face closure or a precarious future, it is not uncommon for community members to explicitly recognize the industries' contributions they once took for granted. In light of the real and perceived vulnerabilities Atikokan faced, provincially elected MPP Bill Mauro recognized that if the AGS had closed due to the provincial coal cessation legislation, the town would have faced an uncertain future.

'After my election it was obvious to me what just a simple closure with no conversion [to biomass wood pellets] would have meant to the community of Atikokan. It would have been quite frankly - at the risk of sounding a bit dramatic - it would have been catastrophic in my opinion'.

Other participants, when considering the potential community impact of an AGS closure, used phrases associated with death and decline such as 'ghost town' and 'final nail in the coffin'. The 'catastrophic' outcomes from the closure would have likely included the loss of a number of socio-economic benefits AGS provides. Brent Boyko, OPG Director of Biomass Development and former AGS Station Manager, outlines some of these benefits.

'Taxes, good jobs, employees' families, but not only that, our [AGS] employees are engaged in the community extensively as well, be it minor hockey or running the ski hill. We have employees that are involved in cross country ski trails, on boards. Basically, there are a lot of folks that are well-engaged in the community'.

The first benefit Boyko mentioned above is taxes. Payments made directly from AGS to the town would have ceased if the generating station had closed, causing a negative impact on town funding. Mayor Brown outlines the extent to which AGS contributes directly to the town.

'The amount of taxes we get from the OPG station (that's called payments in lieu, PILs), is about one-third, it's over, roughly, two million dollars a year. Two million dollars out of the ... we collect approximately six million, and so about one-third.'

With funding reductions of approximately one-third, services to the community would have likely been drastically cut. Other interview participants also recognized AGS's contribution to the town tax base with their estimates ranging from $25 \%$ to $60 \%$ of the community's total tax base. In addition to providing a stable and large 
tax base, AGS provides many well-paying jobs. Garry McKinnon simply states,

'The way that it contributes the local economy is through the employees, through the salaries that it generates, they're probably down to 80 employees now but they average $\$ 100,000$ so there's $\$ 8$ million in the local economy, $\$ 8$ million available to the local economy'.

Other interview participants identify the AGS as 'our major employer', as providing 'a lot of jobs', and those jobs being, 'all pretty good paying jobs'. However, interview participant Daryl Gaudry, AGS Stationary Engineer, recognizes that although some of these AGS jobs will be lost when the conversion to biomass is complete, additional new local indirect jobs will be required and created.

'We will retain employment at Atikokan Generating Station converting to biomass, although staffing levels will probably be 10 less than you would have on coal. Extra jobs will be gained in the direct fueling of [wood] pellets from the pellet industry, additional people in the forest industry and supporting services within the town of Atikokan'.

Maintaining and creating new jobs in and around Atikokan helps retain current workers and their families, which provide positive socio-economic spin-offs. A local newspaper article which included a comment from Mayor Brown acknowledged that AGS employees are, 'a vital part of the social fabric of Atikokan' [16]. Cast in opposite light, Wilf Thorburn, Atikokan Hydro CEO, speculates how the community's population may have declined if the AGS had closed.

'So, without the generating station, we would lose a lot of that fabric that's needed to hold the community together. From that regard, I don't know how you could actually put a figure on it, but I would suggest that we'd probably be down to 1200 or 1500 people or less and shrinking if everything started to fall away'.

With the speculated loss of AGS employees and the social fabric they maintain, Prokopchuk reflects on some of the more obvious contributions which help hold the community together, especially when AGS employees first move to the community.

'They took part in promoting and attending cultural events, social institutions or whatever you want to call them, got on the boards; whether it was the hospital, or tourism. Maybe it was easy for them because they were from outside and got a chance to make some ties. I don't know, I don't think it was directed by OPG by any means, because that doesn't normally work. These people just went beyond the call of duty'.

The AGS's community engagement appears also to be a source of pride for its employees. An AGS employee interview outlines some of the contributions employees make in the community.

'We've built gazebos. We've built park benches. We've built barbeques. We do whatever looks like would be a community service when we're requested, within reason'.

Additional employee contributions, as perceived by other participants, include volunteering as 'hockey coaches and the baseball coaches', and involvement in 'charity campaigns'.

In addition to the abovementioned social contributions and volunteerism, AGS's financial sponsorship of community events seem to be a source of pride for AGS employees. OPG's Brent Boyko outlines some of the sponsored initiatives. 'It goes right from sponsoring pow wows to working with school education programs on sustainability initiatives'. AGS also sponsors the annual Bass Classic which is the biggest event in the community'.

Additionally, Atikokan Centennial Museum has been the beneficiary of a recent AGS-sponsored initiative. A museum staff member commented that they received, '... almost a $\$ 10,000$ grant to put up the OPG exhibit here in the museum'. The exhibit, which presents the historic significance of AGS and its coal era includes, '... a pair of miniature replicas of the station's coal handling, storage, burning and power generation systems' [55]. Additionally, according to Paula Sanders, AEDC Sr. Community Development Advisor, sponsorship initiatives have included, 'contributing to hockey and Entertainment Series, just to name a few'.

Although Flora and Flora's (1990) context was different than Atikokan, they identified a number of important attributes successful communities have, such as having a 'willingness to invest private capital locally' [56]. As recognized by the community, AGS has done this through its sponsorship of community events and other community development initiatives. Communities (such as Atikokan) with residents that recognize and appreciate the broad benefits that primary industries provide may possess the social fabric required to successfully face challenges $[11,57,58]$. 
Atikokan community members recognize AGS's multifaceted role in the community and hence suggest that its loss would have a lasting and obvious effect on the community. This recognition leads into the final theme, that Atikokan has strong community spirit and desire to fight for their town. As will become apparent in the next section, without this community engagement, it is possible that there would have been less political will to convert the AGS to wood pellet biomass.

\section{A strong community spirit and desire to fight for their town}

Community residents' spirit to fight for their town is often spurred on by the recognition that the community faces vulnerabilities such as shrinking populations (suggested earlier in terms of social fabric loss). Warren Paulsen's interview outlines a 50-year trend in Atikokan.

'The mines made some technical changes that allowed them to lay some people off. It was a long series of small layoffs, starting in 1961. We always talk about the mine shutting down, which was $1978,1980 \ldots$ around there. If you do a graph of our population, you can hardly tell where 1980 was. It's just a long gradual ... it's a flat straight line going down from 1961 to today. It's unfortunately still going down. That may have shaped our culture. That's over 50 years of gradual decline. In a sense, it's not a boom/bust economy here'.

Paulsen's observations are corroborated with more current Statistics Canada data. Atikokan's population is approximately 2,800 , but has been on a gradual decline over the past 20 years. In 1991, the population was over $4,000[59,60]$. As a rural population shrinks, there are generally,

'... two options for struggling resource towns like Atikokan. The first is to let the towns die out, implying that local residents abandon their homes and find employment elsewhere. The second is to attempt to revitalize local economies' [61].

During the post-mining era, some community members decided to not give up on their town and let it die out. Dave Elder reflects,

'When the mines closed, this town in 1979 [they] had a choice of packing her in or doing something about it. ... The people that stayed, they were just the kind of people that said we can make this work. The town has never, ever given up on trying to attract, let's say big projects, big operations, and has been successful in a number of cases, not always'.

The desire to not give up but fight may have been a legacy attributed in part to the community's past mining residents ${ }^{\mathrm{d}}$. Mike Lewis, longtime resident and Ad Hoc Energy Committee ${ }^{\mathrm{e}}$ member, provides his view.

'I think it has a lot to do with the culture of the mining people. Mining people came from all over the world, literally, all over the world, to work here. They're a kind of unique people. Those families grew up here and they don't give up on stuff. It's a community thing. It's hard to explain to people. Lots of people can't figure out why we live here. We do because we like it. We want to make sure we keep it alive'.

Although the mine jobs have been gone for years, the community 'fight' has endured to present day, most recently in the wake of a provincial coal cessation policy. MPP Bill Mauro's community observations are telling.

'Most northern communities have this level of cohesiveness and coming together to fight the good fight when there are serious issues affecting the communities. We really have no choice. We're relatively small. We're geographically isolated. If we're not going to fight, there's really nobody else to take up the fight for us'.

Often successful communities have a person or small group of people who lead this fight projecting hope and a vision of how the town can transform into something new. Dave Elder acknowledged one such person who fought to keep Atikokan strong when facing the possible AGS closure.

'It's credit [referring to the conversion to biomass, thus saving AGS] in large part, is to the community leaders of the day, and in particular the current Mayor, Mayor Brown ... he's just been a mainstay of the community, politically anyway'.

Wray Clement, AGS Station Manager, elaborates on Brown's role in mobilizing the community when facing the potential AGS closure.

'Dennis Brown, got committees together, got the right people together, started looking at options, started talking about options and the biomass became one of the bigger possibilities'. 
Furthermore, Brown has been described as 'aggressive in a good way' and as possessing the 'perseverance, tenacity and commitment to the community' [62] required to help make Atikokan successful. In addition to the work of the mayor (and council), Lewis reflects on how the Ad Hoc Energy Committee played an important role in the fight to prevent AGS closure.

'Our general function, at the time, was to fight [Energy Minister] Dwight Duncan and his friend, [Premier of Ontario] McGuinty and make sure they did something here. They made promise after promise, and it took eight years'.

The Ad Hoc Energy Committee initially fought to keep coal as the primary fuel source for the AGS, thus preventing its closure, but as alternatives were considered, woody biomass became a more and more feasible option. Mike Lewis recalls,

'Initially we were looking for ways to keep coal as the energy source through pollution controls and carbon capture, both of which were rejected by the government. We weren't thinking of [wood] pellets, we were thinking of slash and all those other kinds of things that could be burned and how much was there in the bush that could be used. Then, agreement went to pellets'.

Furthermore, it was observed by Angela Sharbot, Town of Atikokan Chief Administrative Officer (CAO), that community residents from the general population were engaged in the fight as well. 'You had the people that were writing letters and Atikokan is a community that fights'. This community fight and support was also recognized by OPG President Tom Mitchell in a newspaper article covering the successful approvals for biomass conversion at AGS.

'This would not have been possible without the unwavering support of this community," Mitchell told a packed lunch room at the plant. "Today, we look forward to working with this community for many, many years to come' [16].

A strong community identity to fight and not give up on the town is also illustrated in a longitudinal study from Utah which investigated how the community of Delta changed over time in light of the establishment of a coal-fired generating station. The study indicated that residents' community attachment and high satisfaction levels helped during periods of change and contributed to weathering the 'thick and thin' [58]. Residents with strong attachment and higher satisfaction levels would potentially be more willing to fight for their community's long-term success. Furthermore, economic shocks (perceived or real) may play a positive role in community cohesion and civic engagement and contribute to the social fabric if residents work together to counter the shock $[54,57]$. This may help explain why Atikokan residents' community spirit and desire to fight for their town lead to their activity which led to the winwin solution which included banning coal while maintaining AGS.

\section{Conclusions}

This research sought to identify Atikokan's historical pre-conditions and community members' attributes and perceptions which lead to the community's response, thusly saving the local thermoelectric generating station in light of new provincial energy legislation. Using a qualitative data analysis approach, emergent themes from the data included i) traditions of resource-based industry congruent with producing and burning forestbased renewable fuels, ii) historical linkages to a strong entrepreneurial ethic, iii) community members' recognition of AGS's multifaceted role in the community and iv) strong community spirit and desire to fight for their town.

Political decision makers can be more effective when creating policies if they have a better understanding of the affected community's history and identity. Increased understanding can help in evaluation and anticipation of a community's response (and readiness for change). During the provincial coal cessation deliberations, it appears that the four emergent community attributes and perceptions provided a foundation for the community response to the potential AGS closure. The cessation of coal and the resultant induction of a new local forest products industry not only created new local jobs, but those jobs also aligned with Atikokan's traditions of resource-based industry. When communities consider new business or entrepreneurial opportunities, an evaluation of community fit and, subsequently, comfort level could be a useful strategy.

Another factor relates to a community's entrepreneurial ethic. Entrepreneurs are often the first people to recognize an opportunity (or threat) and the first to capitalize on that opportunity (or threat). When the conversion from coal to biomass wood pellets started to look like a feasible option, community members with entrepreneurial ability exercised these skills in their efforts to influence decision makers. Although our data does not make a direct correlation between entrepreneurship and the establishment of a local biomass wood pellet supplier, we felt this reoccurring theme could not be ignored, since over time it seems to have 
played an important role in how the community faces challenges.

Furthermore, another emergent community attribute is related to how Atikokan residents appreciate and recognize the multifaceted role of AGS in the community. Beyond providing livelihoods for its employees, AGS provides positive spin-offs when engaging the community through sponsorship of events and other locally important initiatives. AGS has demonstrated that corporate citizenship programing (through sponsorship of community events for example) can foster increased appreciation from all residents and not only the residents who are employed by the industry. When faced with the potential closure and the obvious loss of jobs (and the less obvious loss of corporate citizenship programming), the community rallied to save the AGS.

Finally, when facing potential decline, community residents can passively allow the decline to take place, or they can rally to keep the community vital and thriving, especially if the community possesses a strong community spirit and desire to fight for their town. Communities with these attributes tend to understand the potential threat and engage in rejuvenation efforts [35]. They are often led by a person or small group of people, who organize while projecting hope and a vision of transformation. When facing AGS closure, Atikokan had residents with these characteristics, residents who took up the fight. The efforts of these Atikokan community members played an important role in influencing a climate which secured a stable and predictable employer (and attracting a new employer) for years to come.

The conversion of AGS to biomass wood pellets was not an immediately apparent option when coal cessation policy was first introduced. However, cessation's introduction has created a greater positive socio-economic impact (relative to coal burning) for Atikokan. Burning biomass wood pellets at AGS has become a catalyst creating a new local forest product value chain, while supporting local forest and logging operations. Furthermore, biomass wood pellets are considered a valueadded product relative to wood fibre, which, from a public policy standpoint, is seen as another positive outcome.

'While the traditional economy of Canada has been dominated by the natural resources sector, public policy has signaled an interest to diversify and promote value-added components to address both longer-term resource depletion and the changing markets for Canada's natural resource products (e.g. lumber and pulp and paper manufacturing) [24]'.
Although case studies cannot be generalized, our findings may offer insights for other jurisdictions and should have value beyond Atikokan since other Canadian communities face closure of major employers. Interests in other jurisdictions may consider monitoring Atikokan's future progress since this project is the first of its scale in North America. This study identifies four attributes of one community in one case. Due to the confounding nature of this work, it is unknown if these attributes would be effective in all cases, if they must exist together or if there are other critical attributes not presently identified here. Future research could include testing these findings in other communities facing threats to determine their role in averting economic collapse. Future work could also include a study investigating the three other coal-burning OPG generating stations to identify if the attributes in Atikokan can be found in the other communities.

\section{Endnotes}

${ }^{\mathrm{a}}$ Biomass defined herein is as plant-based products harvested from Ontario's forests for the purpose of thermoelectric energy production.

${ }^{\mathrm{b}}$ The Atikokan Progress has been publishing local news content weekly since 1950. Criteria for article selection included stories which mentioned the AGS conversion, the community concern about the AGS, the entrepreneurial and local market conditions and the potential pellet suppliers.

${ }^{\mathrm{c}}$ Atikokan Renewable Fuels initiated the development of the wood pellet plant in Atikokan, but since the writing of this news article, ARF was purchased by Rentech, Inc.

${ }^{\mathrm{d}}$ It must be noted that other mining communities in the region such as Manitouwadge, Ontario, and Silver Islet, Ontario, have not been as resilient and have closed.

${ }^{\mathrm{e}}$ The Ad Hoc Energy Committee is a town-level committee whose activities included lobbying provincial government to maintain a stable energy production and distribution system in northern Ontario, which ultimately led to the conversion of the AGS from burning coal to burning biomass wood pellets.

\section{Appendix}

\section{Selected codes relevant to the current study}

Since this manuscript is part of a larger study, coded data (and nested coded data) which contributed to the manuscript's four themes are included below. Upper level codes may not sum the lower level codes due to overlap coding and not all codes in the overall study were included in the present manuscript (due to the overall study's broader scope beyond this manuscript). Note: Counts presented here are totals of coded data occurrences, unlike Table 1 values which represent source counts. 
Manuscript heading: Traditions of resource-based industry congruent with producing and burning forest-based renewable fuels

Coding structure: Industries $(n=496)$

Forest-related industries $(n=169)$

Forest products $(n=113)$

Forestry $(n=56)$

Manuscript heading: Historical and current linkages to a strong entrepreneurial ethic

Coding structure:

Entrepreneurship $(n=161)$

Community necessity $(n=10)$

Counter-entrepreneurship $(n=9)$

Examples $(n=61)$

Government or agency's role $(n=9)$

Isolated from other markets $(n=16)$

Underlying factors $(n=56)$

Manuscript heading: Community members' recognition of AGS's multifaceted role in the community

Coding structure: $\quad$ OPG/AGS's role in the community $(n=135)$

Corporate donations $(n=22)$

Educated professionals living in community $(n=3)$

High-paying jobs $(n=29)$

Municipal taxes $(n=31)$

Socio-economic $(n=15)$

Volunteerism $(n=25)$

Manuscript heading: A strong community spirit and desire to fight for their town

Coding structure: $\quad$ Small town challenges and opportunities $(n=499)$

Community fight $(n=64)$

\section{Abbreviations}

AEDC: Atikokan Economic Development Corporation; AGS: Atikokan Generating Station; AID: Atikokan Industrial Development; CAO: Chief Administrative Officer; MPP: Member of Provincial Parliament; MW: megawatts; OPG: Ontario Power Generation.

\section{Competing interests}

The authors declare that they have no competing interests.

\section{Authors' contributions}

All authors have made substantive intellectual contributions to this study. The lead author under the academic tutelage of the other three authors collaboratively developed i) the field data collection methods and ii) the content analysis of field data. All authors contributed to the drafting of the final manuscript, and all provided critical revisions and technical input. All authors read and approved the final manuscript.

\section{Acknowledgements}

The corresponding author, a PhD candidate during this phase of the project, was funded by an Ontario Graduate Scholarship. Additional funding was provided by the Centre for Research and Innovation in the Bio-Economy (CRIBE). The authors are very grateful for the ongoing support to this project provided by Daryl Gaudry, Brent Boyko, Jane Todd and the entire staff at OPG Thunder Bay and Atikokan Generating Stations. Furthermore, the authors also wish to thank all community members from the Town of Atikokan who so freely shared their perceptions which helped the authors to identify and elucidate the historical community pre-conditions which created a cultural climate conducive for the conversion, and by providing insight into the community's role in affecting decisions at AGS.

\section{Author details}

${ }^{1}$ Faculty of Natural Resources Management, Lakehead University, 955 Oliver Road, Thunder Bay, Ontario P7B 5E1, Canada. ${ }^{2}$ School of Outdoor Recreation Parks and Tourism, Lakehead University, 955 Oliver Road, Thunder Bay, Ontario P7B 5E1, Canada.

Received: 23 May 2014 Accepted: 14 November 2014 Published online: 03 December 2014

\section{References}

1. Bollman RD (2001) Definitions of rural. Rural and small town. Canada Analysis Bulletin. Catalogue no. 21-006-XIE 3(3):1-17

2. Tiepoh MGN, Reimer B (2004) Social capital, information flows, and income creation in rural Canada: a cross-community analysis. J Socio-Economics 33:427-448

3. Besser TL (2009) Changes in small town social capital and civic engagement. J Rural Stud 25:185-193

4. Canadian Broadcasting Corporation (CBC) (2013) Coming of age in a canoe. The National. Broadcast date: Oct. 21, 2005. http://www.cbc.ca/archives/ categories/lifestyle/leisure/a-passion-for-paddling-canoeing-in-canada/ coming-of-age-in-a-canoe.html. Accessed 27 Apr 2014

5. OPG Ontario Power Generation (2012) Atikokan Generating Station. http://www. opg.com/generating-power/thermal/stations/atikokan-station/Atikokan\% 20biomass\%20con\%20pdfs/atikokanbrochure.pdf. Accessed 3 Dec 2014

6. OPG Ontario Power Generation (2011) Lambton Generating Station. http://192.75.131.106/power/thermal/brochures/lambtonbrochure.pdf. Accessed 3 Dec 2014

7. OPG Ontario Power Generation (2012) Nanticoke Generating Station http://192.75.131.106/power/thermal/brochures/Nanticoke\%20Brochure\% 20Final\%20Jan.\%202012.pdf. Accessed 3 Dec 2014

8. OPG Ontario Power Generation (2012) Thunder Bay Generating Station conversion project fact sheet. http:/www.opg.com/generating-power/ thermal/stations/thunder-bay-station/Documents/station_brochure.pdf. Accessed 3 Dec 2014

9. Dampier JEE, Shahi C, Lemelin RH, Luckai N (2013) From coal to wood thermoelectric energy production: a review and discussion of potential socio-economic impacts with implications for Northwestern Ontario, Canada. Energy Sustainability Soc doi:10.1186/2192-0567-3-11

10. Canadian Broadcasting Corporation (CBC) (2013) Wynne says Liberals will try to ban coal-fired electricity. http://www.cbc.ca/news/canada/toronto/ wynne-says-liberals-will-try-to-ban-coal-fired-electricity-1.2435647. Accessed 3 Sept 2014

11. Lucas RA (1971) Minetown, milltown, railtown: life in Canadian communities of single industry. Oxford University Press, Oxford

12. Consultants Ltd SENES (2004) Environmental assessment of new energy supply for Atikokan, Ontario: terms of reference, supplementary documents, background information. SynFuel Technologies, Richmond Hill

13. Anonymous (1980) Forestry now major employer: 466 jobs produced in Atikokan since mines shut down - Ross. Atikokan Progress Sept 17:1980

14. Anonymous (2009) Forestry collapse tops AEDC agenda. Atikokan Progress. May 4, 2009. http://atikokanprogress.ca/2009/05/04/forestry-collapse-topsaedc-agenda/. Accessed 3 Dec 2014

15. Ontario Power Generation (OPG) (2011) Atikokan Generating Station biomass repowering project fact sheet. Ontario Power Generation, Toronto

16. McKinnon M (2012) OPG celebrates the conversion of the Atikokan Generating Station. Atikokan Progress. October 18, 2013. http://atikokan progress.ca/2012/10/18/opg-celebrates-the-conversion-of-the-atikokangenerating-station/. Accessed 27 Apr 2014

17. Ontario Centres of Excellence (2012) Success story. Atikokan Bio-Energy Research Centre (ABRC). http://www.oce-ontario.org/our-companies/ success-story/2012/01/09/atikokan-bio---energy-research-centre-\%28abrc\%29. Accessed 3 Dec 2014

18. Ontario (2007) Cessation of coal use. Ontario Regulation 496/07. http://www.e-laws.gov.on.ca/html/regs/english/elaws_regs_070496_e.htm. Accessed 27 Apr 2014

19. Forest BioProducts Inc (2006) Assessment of the viability of exploiting bio-energy resources accessible to the Atikokan Generation Station in Northwestern Ontario: final report. Ontario Ministry of Energy, Sault Ste. Marie

20. Marshall L, Fralick C, Gaudry D (2010) OPG charts move from coal to biomass. Power 154. http://www.powermag.com/opg-charts-move-fromcoal-to-biomass/. Accessed 27 Apr 2014 
21. OPG Ontario Power Generation (2013) Electricity from biomass community update: Atikokan Generating Station Biomass Conversion Project. http://192.75.131.106/power/thermal/fuelconversion/Biomass\%20Fact\% 20Sheet_May\%202013.pdf. Accessed 3 Dec 2014

22. Ashton WS (2009) The structure, function, and evolution of a regional industrial ecosystem. J Ind Ecol 13(2):228-246

23. Beshiri R (2010) Manufacturing employment in resource value chains: a rural-urban comparison from 2001 to 2008. Rural and Small Town Canada Analysis Bulletin, Statistics Canada 8(5):1-34

24. Rosehart RG (2008) Northwestern Ontario: preparing for change. Northwestern Ontario Economic Facilitator Report. Queen's Printer for Ontario, Thunder Bay

25. O'Hagan S, Cecil B (2007) A macro-level approach to examining Canada's primary industry towns in a knowledge economy. J Rural and Community Dev 2:18-43

26. de Gomez W, Bullock R (2012) Civil society in Canada: a case study of rural and urban planning contexts. Soc Sci J 49:202-209

27. Harris S, Alasia A, Bollman RD (2008) Rural commuting: its relevance to rural and urban labour markets. Rural and Small Town Canada Analysis Bulletin Statistics Canada 7(6):23

28. Lawrie M, Tonts M, Plummer P (2011) Boomtowns, resource dependence and socio-economic well-being. Aust Geogr 42(2):139-164

29. Woodrow M (2002) Challenges to sustainability in Northern Ontario: challenge paper. Environmental Commissioner of Ontario, Toronto

30. Alasia A, Hardie DJ (2011) Employment shifts in natural resource sectors: a focus on rural value chains. Rural and Small Town Canada Analysis Bulletin Statistics Canada 8(7):1-58

31. Hayter R (2000) Single industry resource towns. In: Sheppard E, Barnes TJ (eds) A companion to economic geography. Blackwell, Oxford

32. Turcotte M (2005) Social engagement and civic participation: are rural and small town populations really at an advantage? Rural and Small Town Canada Analysis Bulletin. Statistics Canada 6(4):1-24

33. Besser T (2013) Resilient small rural towns and community shocks. J Rural and Community Dev 8:117-134

34. Markey S, Halseth G, Manson D (2008) Challenging the inevitability of rural decline: advancing the policy of place in northern British Columbia. J Rural Stud 24:409-421

35. Dahms FA (1995) 'Dying villages', 'counterurbanization' and the urban fielda Canadian perspective. J Rural Stud 11:21-33

36. Ritchie J, Lewis J, Elam G (2003) Designing and selecting samples. In: Ritchie J, Lewis J (eds) Qualitative research practice: a guide for social science students and researchers. SAGE, London

37. DiCicco-Bloom D, Crabtree BF (2006) The qualitative research interview. Med Educ 40:314-321

38. Krippendorff K (2004) Content analysis: an introduction of its methodology. SAGE, Thousand Oaks

39. Saldana J (2009) The coding manual for qualitative researchers. SAGE, Los Angeles

40. Atikokan Economic Development Corporation (2013) Atikokan Economic Development Corporation. http://atikokaninfo.com/aedc/. Accessed 13 Dec 2013

41. QSR International Pty Ltd (2012) NVivo qualitative data analysis software; version 10. QSR International Pty Ltd., Doncaster

42. Elo S, Kyngas $H$ (2008) The qualitative content analysis process. JAN Research Methodology 62(1):107-115

43. Berg BL, Lune H (2012) Qualitative research methods for the social sciences. Pearson, Upper Saddle River

44. McEvoy J, Gustafson J (1985) History through participation: why do people stay in Atikokan? Atikokan Centennial Museum: Ontario Youth Corps Program, Atikokan

45. Paulsen W (1993) The little town that could: how leadership and community involvement reshaped Atikokan after an economic tragedy. Atikokan Economic Development Corporation \& Atikokan Futures, Atikokan

46. McKinnon M (2010) Optimism prevails at economic development agency's annual meeting. Atikokan Progress. May 11, 2010. http://atikokanprogress. ca/2010/05/11/optimism-prevails-at-economic-development-agencysannual-meeting/. Accessed 27 Apr 2014

47. Southcott C (2008) The changing occupational structure of Northern Ontario: Census Research Paper Series 2006. Northern Ontario and the Algoma Workforce Investment Committee: Ontario Ministry of Training, Colleges and Universities, Thunder Bay
48. Akamani K (2012) A community resilience model for understanding and assessing the sustainability of forest-dependent communities. Hum Ecol Rev 19(2):99-109

49. Freudenburg WR, Gramlin R (1992) Community impacts of technological change: toward a longitudinal perspective. Soc Forces 70(4):937-955

50. Dabson B (2001) Supporting rural entrepreneurship. Exploring policy alternatives for a new rural America. Proceedings of a conference sponsored by Federal Reserve Bank of Kansas City. Center for the Study of Rural America, Kansas City

51. Drucker PF (2006) Innovation and entrepreneurship. Harper Business, New York

52. Matarrita-Cascante D, Trejos B (2013) Community resilience in resourcedependent communities: a comparative case study. Environ Plan 45:1387-1402

53. Gladwin CH, Long BF, Babb EM, Beaulieu L, Moseley A, Mulkey D, Zimet DJ (1989) Rural entrepreneurship: one key to rural revitalization. Am J Agriculture Economics 71:1305-1314

54. Redlin M, Aguiar G, Langelett G, Gerald W (2010) "Why are you still out there?" Persistence among deep rural communities in the Northern Plains. Online J Rural Res Policy 5(5):1-22

55. Smith J (2013) Coal in Atikokan: it's history now. Atikokan Progress. June 21, 2013. http://atikokanprogress.ca/2013/06/21/coal-in-atikokan-its-history-now/. Accessed 27 Apr 2014

56. Flora CB, Flora JL (1990) Developing entrepreneurial rural communities. Sociological Practice 8(1):197-207

57. Besser TL, Recker N, Agnitsch K (2008) The impact of economic shocks on quality of life and social capital in small towns. Rural Sociol 73(4):580-604

58. Brown RB, Dorius SF, Krannich RS (2005) The boom-bust-recovery cycle: dynamics of change in community satisfaction and social integration in Delta, Utah. Rural Sociol 70(1):28-49

59. Statistics Canada (1996) Census of population. Statistics Canada Catalogue no. 95F0181XDB96001. http://www12.statcan.ca/english/census96/data/ profiles/Rp-eng.cfm?LANG=E\&APATH=3\&DETAIL=0\&DIM=0\&FL=A\&FREE= $0 \& G C=0 \& G I D=0 \& G K=0 \& G R P=1 \& P I D=35782 \& P R I D=0 \& P T Y P E=3 \& S=0 \&$ SHOWALL $=0 \& S U B=0 \&$ Temporal $=1996 \&$ THEME $=34 \& V I D=0 \& V N A M E E=\&$ VNAMEF=. Accessed 14 Dec 2013

60. Statistics Canada (2012) Atikokan, Ontario (Code 3559001) and Rainy River Ontario (Code 3559) (table). Census profile. 2011 Census. Statistics Canada Catalogue no. 98-316-XWE. Ottawa. Released October 24, 2012. http://www12.statcan.gc.ca/census-recensement/2011/dp-pd/prof/index. cfm?Lang=E. Accessed 14 Dec 2013

61. Ellis P, Fiddler C, Gill R, Keyworth G, Moretti M, Paske J, Phillips L, Te Z, Vandebelt D, Wright B (2003) Onwards Atikokan: the renewal of an ex-single-industry town. Faculty of Environmental Studies. University of Waterloo, Waterloo

62. Anonymous (2009) Atikokan Renewable Fuels aims for pellet production to start in early 2010. Atikokan Progress. June 29, 2009. http://atikokanprogress. ca/2009/06/29/atikokan-renewable-fuels-aims-for-pellet-production-to-startin-early-2010/. Accessed 27 Apr 2014

\section{doi:10.1186/s13705-014-0026-4}

Cite this article as: Dampier et al: Small town identity and history's contribution to a response in policy change: a case study of transition from coal to biomass energy conversion. Energy, Sustainability and Society 2014 4:26.

\section{Submit your manuscript to a SpringerOpen ${ }^{\odot}$ journal and benefit from:}

- Convenient online submission

Rigorous peer review

- Immediate publication on acceptance

- Open access: articles freely available online

- High visibility within the field

- Retaining the copyright to your article

Submit your next manuscript at $>$ springeropen.com 